\title{
Kommission Hüftsonografie SGUM
}

Im Dezember ist wegen anstehender Probleme eine Sondersitzung der Kommission vorgesehen. Immer wieder treten Probleme mit der Anerkennung ausländischer Weiter- und Fortbildungen auf, insbesondere bei erfahrenen Hüftsonografen, welche sich in der Schweiz niederlassen wollen und die nicht immer mit den hier herrschenden Vorschriften vertraut sind. Das vom Schweizerischen Institut für Weiterund Fortbildung (SIWF) akkreditierte Fähigkeitsprogramm schreibt die Anforderungen genau vor: An diese haben sich nicht nur die Schweizerischen Kolleginnen und Kollegen, sondern auch die aus dem Ausland eingewanderten zu halten.

Beat Dubs

Präsident Kommission Hüftsonografie 